\title{
Separation and Recovery of Potassium Chloride from Sintering Dust of Ironmaking Works
}

\author{
Cui PENG, Fuli ZHANG and Zhancheng GUO \\ Key Laboratory of Ecological and Recycle Metallurgy, University of Science and Technology, Beijing, 100083, China. \\ E-mail: zcguo@metall.ustb.edu.cn
}

(Received on January 16, 2009; accepted on March 6, 2009)

\begin{abstract}
Sintering plant in iron and steel making company generates very fine metal-containing dusts which can present major environmental problems. This paper describes experimental work on a relatively simple and inexpensive process for recovering the potassium chloride and upgrading the iron level of dust from a Chinese plant, to produce saleable potassium chloride product and environmentally safe waste products for reuse. The dust contained about $10-20 \%$ potassium as potassium chloride, $20 \%$ iron as iron oxides, plus small quantities of lead, copper, cadmium, zinc and other materials. Individual particles of the dust were commonly aggregates of various shapes. Multi-stage countercurrent leaching was taken to completely remove potassium chloride in the ESP dust, but leave iron in the leach residual. With the help of sodium sulfide precipitation, the leached heavy metals were removed from the leaching solutions and a mixture solution which can be perceived as system $\mathrm{KCl}-\mathrm{NaCl}-\mathrm{CaCl}_{2}-\mathrm{H}_{2} \mathrm{O}$ was left. Then potassium chloride in the system can be separated and recovered by fractional crystallization. At last the mother liquor was returned to the leaching process as leaching agent together with new tap water. This proposed flow sheet was proved feasible through construction of the demonstration unit in the lab, and $\mathrm{KCl}$ product with a purity of $96.5 \%$ was obtained.
\end{abstract}

KEY WORDS: ESP dust; water leaching; potassium chloride; waste management.

\section{Introduction}

Potassium chloride has wide applications in various areas, such as in agriculture as basis and additional fertilizer of some crops, in industry as raw material of various non-chlorine potassium fertilizers and in medical area for preventing and curing kaliopenia. In China, potassium chloride production, which is mainly come from Qinghai saline lake, is a far cry from meeting the demands of agriculture and industry, and statistics show that approximately $80 \%$ of potassium fertilizer required is counted on imports. On the other hand, price of potassium chloride has increased progressively in the past four years, with the annual speed of about $20 \%$, which is undoubtedly the result of integration of resource shortage and market discipline. Therefore, it is pressing to find new potassium sources to relieve the short supply of potassium chloride.

Fortunately, it was found that ESP dust (a metallurgical dust arrested by electrostatic precipitator in the sintering process of iron and steel making) containing about 10-20\% (weight percent) potassium as potassium chloride. ${ }^{1)}$ There is no doubt that if the potassium chloride in the sintering dust could be extracted and recovered, great contributions would be made to the potassium industry, since the total amount of this kind of dust increases with ever-rising steel production. According to statistics, $4 \mathrm{~kg}$ of the dust was produced for making per ton steel, that is, about 1.96 mil- lion ton of the potassium-enriched dust was generated in China with annual steel production of about 0.49 billion ton, which means approximately 500000 ton potassium chloride contained.

The rapid growth of both global economy and world population make addition to the resource shortage, so research and development of resource recycling reuse technologies have been paid a great deal of attention. For instance, there are a lot of investigators who dedicated to regeneration of valuable elements out of a great variety of industrial wastes such as carbon steel EAF dust, ${ }^{2-8)}$ electronic waste, ${ }^{9)}$ MSWI etc. ${ }^{10-13)}$ And the processing methods involve pyrometallurgy, hydrometallurgy and biometallurgy. ${ }^{14)}$ The target elements are zinc, iron, carbon, copper, gold and so on. ${ }^{15-19)}$ However, seldom literature involved the recovery of potassium from the industrial dust, not to mention from the sintering dust. In this work, an attempt to recover potassium chloride from the sintering dust by a series of hydrometallurgical processes including leaching, precipitating, evaporating and crystallization has been made. It is found that the potassium chloride contained in the dust can be recovered with the proposed simple and inexpensive flow sheet, which is also proved feasible by the pilot tests with $\mathrm{KCl}$ product purity of $96.5 \%$. 


\section{Experimental Procedurals}

\subsection{Sampling and Component Analysis}

ESP dust sampled from three iron and steel companies are subjected to chemical analysis to determine mass contribution of potassium. In addition, one of them was selected as the material of the following extraction and separation tests. At first the composition of the selected ESP dust sample was analyzed. The sample was mixed with acid mixture $\left(\mathrm{HNO}_{3}: \mathrm{HClO}_{4}: \mathrm{HF}=5: 3: 2, \mathrm{v} / \mathrm{v}\right)$ in a Teflonlined closed vessel and placed in a high-pressure digestion oven at $170^{\circ} \mathrm{C}$ for $5 \mathrm{~h}$. The digested acid mixture was analyzed to determine the trace elements. A Perkine-Elmer OPTIMA 3000 ICP-AES was used to determine the Al, $\mathrm{Ca}, \mathrm{Fe}, \mathrm{K}$, $\mathrm{Mg}, \mathrm{Na}, \mathrm{Pb}, \mathrm{Cu}, \mathrm{Ni}$ and $\mathrm{Zn}$ concentrations. ${ }^{1)}$

\subsection{Sizing Analysis}

Particle size distributions of the un-washed and waterwashed head sample were measured using a Laser Granulometer model SEISHIN LMS-30 made in Japan.

\subsection{Scanning Electron Microscopy (SEM) and Micro- analysis}

Samples of the dust (both as-received and after water washing) were examined under a scanning electron microscope (SEM) and X-ray mapping via SEM to help gain a better understanding of the ESP dust. The as-received dust samples were directly stuck to conductive adhesive and coated with gold for SEM analysis with CAMBRIDGE S360, Tracer Northern. For X-ray mapping, the samples were pressed in an organic resin by cold cure, grounded with silicon carbide paper, polished with diamond suspension and coated with carbon. The prepared samples were subjected to the X-ray mapping via SEM for elements $\mathrm{Cl}, \mathrm{K}, \mathrm{Fe}, \mathrm{Ca}$ and $\mathrm{O}$.

\subsection{Surface Area and Porosity Measurements}

Surface area and porosity measurements of samples were made using the BET technique on a Quantachrome Autosorb-1 instrument. This methods uses nitrogen adsorption (at liquid nitrogen temperatures) to measure the surface area of interstitial pores within powder or granule samples. Both single and multi-point measurements were made to give a more accurate value.

\subsection{Water Leaching and Impurities Removing Experi- ments}

All the water leaching tests were conducted in a Jacketed PMMA reactor with four baffles. Effect of leaching temperature, dust particle size, liquid solid ratio and stirring speed on leaching rate of potassium chloride and impurities were investigated. Only part of the results was shown in this paper. Counter-current leaching was applied in this leaching process so as to increase the potassium chloride concentration in the leaching liquor. Then proper amount of sodium sulfide was added to the prepared leaching liquor to remove heavy metals, and the addition amount of the sodium sulfide and the required precipitation time were also optimized.

\section{Results and Discussion}

\subsection{Possible Mechanism of KCl Formation}

Sintering converts the powdered iron ores into an agglomerate, which posseses the necessary strengh and gas permeability for efficient high-productivity blast furnace operation. The process is carried out by wet mixing a carefully blended mixture of fine iron ores with $3-5 \mathrm{wt} \%$ of coke breeze and other additives, such as limestone, lime chloride, olivine and recycled ferruginous dusts from upstream processes. Sintering process is energy intensive and produces a considerable amount of carbon dioxide from the combustion of solid fossil fuels. The peak temperature in the combustion zone reaches $1300-1480^{\circ} \mathrm{C}$. So a variety of reactions occur in the sintering process, mianly including reduction reaction of iron oxides, coke combustion and decomposition of some complex componds.

Generally, there are many sillico aluminates in the iron ore which contain potassium element, such as feldspar $\left(\mathrm{K}_{2} \mathrm{Al}_{2} \mathrm{Si}_{6} \mathrm{O}_{16}\right)$, leucite $\left(\mathrm{K}_{2} \mathrm{Al}_{2} \mathrm{Si}_{4} \mathrm{O}_{12}\right)$, six-party potassium stone $\left(\mathrm{K}_{2} \mathrm{Al}_{2} \mathrm{Si}_{2} \mathrm{O}_{4}\right)$, mica $\left(\mathrm{KH}_{2} \mathrm{Al}_{2} \mathrm{SiO}_{12}\right)$ and so on. It is speculated that the following reactions may occur in the sintering process at the elevated temperature with the reducing atomsphere (boiling point of potassium is $774^{\circ} \mathrm{C}$ ),

$$
\begin{aligned}
& \mathrm{K}_{2} \mathrm{O} \cdot \mathrm{Al}_{2} \mathrm{O}_{3} \cdot 6 \mathrm{SiO}_{2}+\mathrm{C}+12 \mathrm{CaO} \\
& \quad=5\left(2 \mathrm{CaO} \cdot \mathrm{Si}_{2} \mathrm{O}\right)+2 \mathrm{CaO} \cdot \mathrm{Al}_{2} \mathrm{O}_{3} \cdot \mathrm{SiO}_{2}+2 \mathrm{~K} \uparrow+\mathrm{CO} \uparrow \\
& \mathrm{K}_{2} \mathrm{O} \cdot \mathrm{Al}_{2} \mathrm{O}_{3} \cdot 2 \mathrm{SiO}_{2}+\mathrm{C}+4 \mathrm{CaO} \\
& \quad=2 \mathrm{CaO} \cdot \mathrm{Si}_{2} \mathrm{O}+2 \mathrm{CaO} \cdot \mathrm{Al}_{2} \mathrm{O}_{3} \cdot \mathrm{SiO}_{2}+2 \mathrm{~K} \uparrow+\mathrm{CO} \uparrow
\end{aligned}
$$

The potassium vapor is oxided rapidly by the aircurrent through the material bed,

$$
4 \mathrm{~K}+\mathrm{O}_{2}=2 \mathrm{~K}_{2} \mathrm{O} \uparrow
$$

Then $\mathrm{K}_{2} \mathrm{O}$ reacts with acidic oxide $\mathrm{SiO}_{2}$,

$$
\mathrm{K}_{2} \mathrm{O}+\mathrm{SiO}_{2}=\mathrm{K}_{2} \mathrm{SiO}_{3}
$$

Some of the produced potassium silicate is reduced by the coke breeze and repeats the above experience, and others may react with potasium chloride as:

$$
\mathrm{K}_{2} \mathrm{SiO}_{3}+\mathrm{CaCl}_{2}=2 \mathrm{KCl} \uparrow+\mathrm{CaO}+\mathrm{SiO}_{2}
$$

Thus $\mathrm{KCl}$ is formed and de-dusted by means of an electrostatic precipitator. This mechenism was confirmed right with HSC software.

\section{2. $\mathrm{KCl}$ Contribution in the ESP Dust}

To investigate the rule of potassium contribution in the ESP dust, seven kinds of ESP dusts were sampled from three steel companies (Baotou Steel, Ji'nan Steel and Laiwu Steel), including one from Baotou Steel, three from Ji'nan Steel and the other three from Laiwu Steel. Ordinal numbers 1st, 2nd and 3rd in Table 1 represent three steps of electrostatic precipitation. It is clear to see that in the 2 nd and 3rd step, ESP dusts contain more than $20 \%$ of $\mathrm{KCl}$, even $40 \%$ in the 3 rd step. As to Baotou Steel, the dust sampled is mixture of the three steps dusts, and $\mathrm{KCl}$ contribution is $17.11 \%$, still a high contribution. However, $\mathrm{NaCl}$ contribution is far lower than $\mathrm{KCl}$ contribution, although the same distributed rule presented as that of $\mathrm{KCl}$.

The 2nd step ESP dust of Laiwu Steel was selected as 
Table 1. $\mathrm{KCl}$ and $\mathrm{NaCl}$ contribution in the ESP dust of three iron and steel companies.

\begin{tabular}{lccccccc}
\hline & $\begin{array}{c}\text { Baotou Steel } \\
\text { Mixture }\end{array}$ & $1^{\mathrm{st}^{*}}$ & $2^{\text {nd }}$ & $3^{\mathrm{rd}^{*}}$ & $1^{\mathrm{st}^{*}}$ & $2^{\text {nd }}$ & $3^{\mathrm{rd}^{\mathrm{r} *}}$ \\
\hline $\mathrm{KCl}, \mathrm{wt} \%$ & 17.11 & 3.49 & 19.45 & 39.76 & 2.55 & 19.75 & 40.05 \\
$\mathrm{NaCl}, \mathrm{wt} \%$ & 1.89 & 0.41 & 1.65 & 3.50 & $/$ & 2.49 & 6.43 \\
\hline$*$ Ordinal numbers 1st, 2nd and 3rd represent the ESP dust arrested by the first, the second and the \\
third step electrostatic precipitator
\end{tabular}

Table 2. Elemental concentrations in the ESP dust.

\begin{tabular}{ccccccccc}
\hline Elements & $\mathrm{K}$ & $\mathrm{Na}$ & $\mathrm{Ca}$ & $\mathrm{Mg}$ & $\mathrm{Zn}$ & $\mathrm{Pb}$ & $\mathrm{Fe}$ & $\mathrm{C}$ \\
\hline Composition,wt\% & 11.50 & 1.48 & 6.71 & 1.002 & 0.20 & 0.885 & 21.73 & 2.76 \\
\hline Elements & $\mathrm{Si}$ & $\mathrm{S}$ & $\mathrm{Al}$ & $\mathrm{Cu}$ & $\mathrm{Mn}$ & $\mathrm{Ti}$ & $\mathrm{P}$ & $\mathrm{Ni}$ \\
\hline Composition,wt\% & 1.762 & 1.21 & 4.56 & 0.041 & 0.132 & 0.060 & 0.065 & $/$ \\
\hline
\end{tabular}

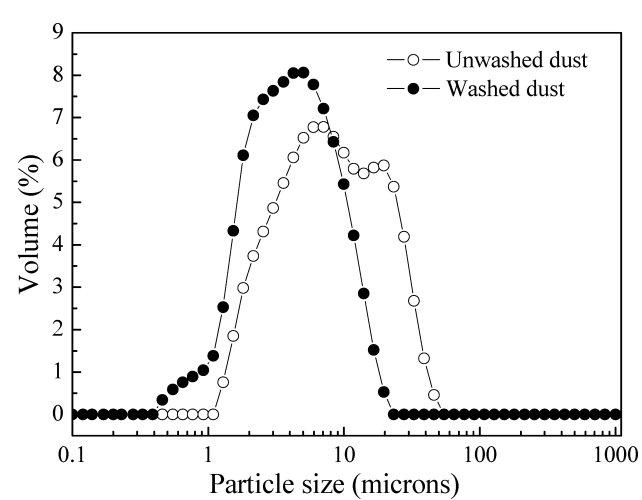

Fig. 1. Sizing analyses of un-washed and washed dust.

material of the following experiments. And the elemental contribution of the dust is given in Table 2. ${ }^{1)}$

\subsection{Sizing Analyses}

Sizing results on the main head sample are shown in Fig. 1. The size distribution of the unwashed dust was bi-modal, with peaks at $7.1 \mu \mathrm{m}$ and $19.7 \mu \mathrm{m}$. The P90 value was approximately $26.4 \mu \mathrm{m}$. Water-washed dust was found to have a P90 of approximately $11.4 \mu \mathrm{m}$. This lower value was probably caused by the removal of soluble salts which were helping to hold together some of the particles, or because some of the water-soluble salts (up to $40 \%$ of the weight) were themselves relatively coarse. The smallest particles recorded in the size analyses were in the $1.29-1.53 \mu \mathrm{m}$ size range in the unwashed dust and in the $0.46-0.55 \mu \mathrm{m}$ range in the washed dust. The largest particles, which were aggregates of small particles as shown below, were in the $38.9-46.1 \mu \mathrm{m}$ size range in the unwashed dust where as they were in the $16.6-19.7 \mu \mathrm{m}$ size range in the washed dust.

\subsection{SEM and X-ray Mapping Analyses}

Selected SEM images of as-received ESP dust are given in Fig. 2. As shown in Fig. 2(a), although many very fine individual particles are present $(1.29 \mu \mathrm{m}$ as noted earlier), larger particles up to $40 \mu \mathrm{m}$ are also present. These larger particles are composites or agglomerates of particles ranging in size from $1 \mu \mathrm{m}$ to about $10 \mu \mathrm{m}$ of various shapes. Figure 2(b) clearly presents how the small or large particles
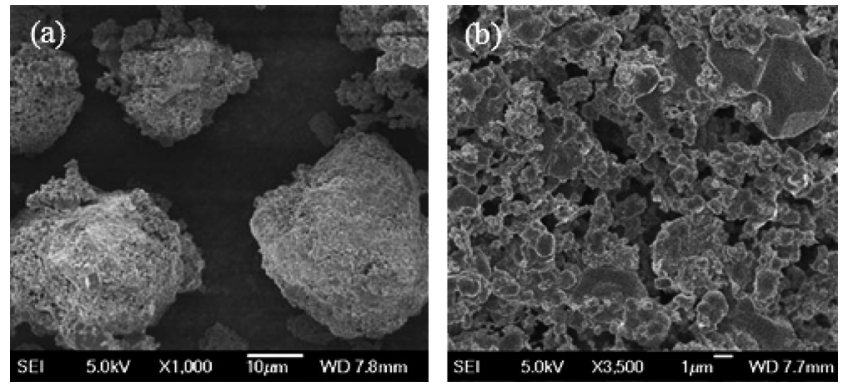

Fig. 2. SEM images of typical agglomerate in as-received (unwashed) ESP dust with (a) magnification $\times 1000$ and (b) magnification $\times 3500$.

agglomerate in the dust by a larger magnification factor of 3500 .

In order to investigate whether there was some difference between the distribution of several major elements in the dust before and after water washing, elements $\mathrm{Cl}, \mathrm{K}, \mathrm{Ca}, \mathrm{Fe}$ and $\mathrm{O}$ distribution were observed by SEM X-ray mapping, as illustrated in Figs. 3 and 4. It can be easily seen that $\mathrm{Cl}$ and $\mathrm{K}$ were distributed in the same way corresponding to a square particle, confirming $\mathrm{KCl}$ presence in the as-received ESP dust, so it is not difficult to understand elements $\mathrm{Cl}$ and $\mathrm{K}$ contribution decreasing drastically after water washing. Distribution of $\mathrm{Cl}$ seems wider than $\mathrm{K}$, suggesting that there are some other chlorides in the dust except $\mathrm{KCl}$, which was verified by composition analysis of water leaching liquor. Another interesting result is the apparent enrichment of elements $\mathrm{Fe}$ and $\mathrm{Ca}$ distribution after water washing. These phenomena observed reflect the advantages of water leaching to dispose the ESP dust. On one hand, $\mathrm{KCl}$ was transferred into the leaching liquor with element Fe left in the leaching residual, thus they are separated; on the other hand, most of the $\mathrm{Cl}$ is removed after water washing, since most of the chlorides are water soluble. This was an important finding as one of the aims of this work was to find a way to reduce chloride level of the dust to make the product more acceptable to the sinter.

\subsection{Surface Area and Porosity Analyses}

The surface area and porosity analyses of the ESP dust sample are given in Table 3. These results show that the head sample has moderate surface area overall but quite 

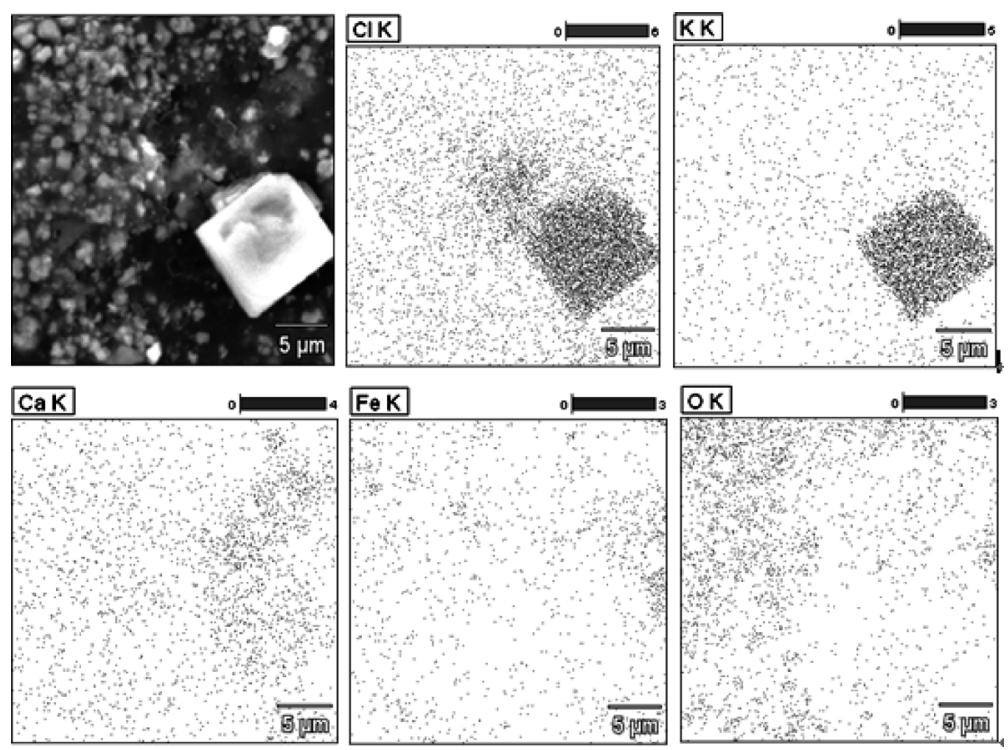

Fig. 3. SEM X-ray mapping of the as-received dust.
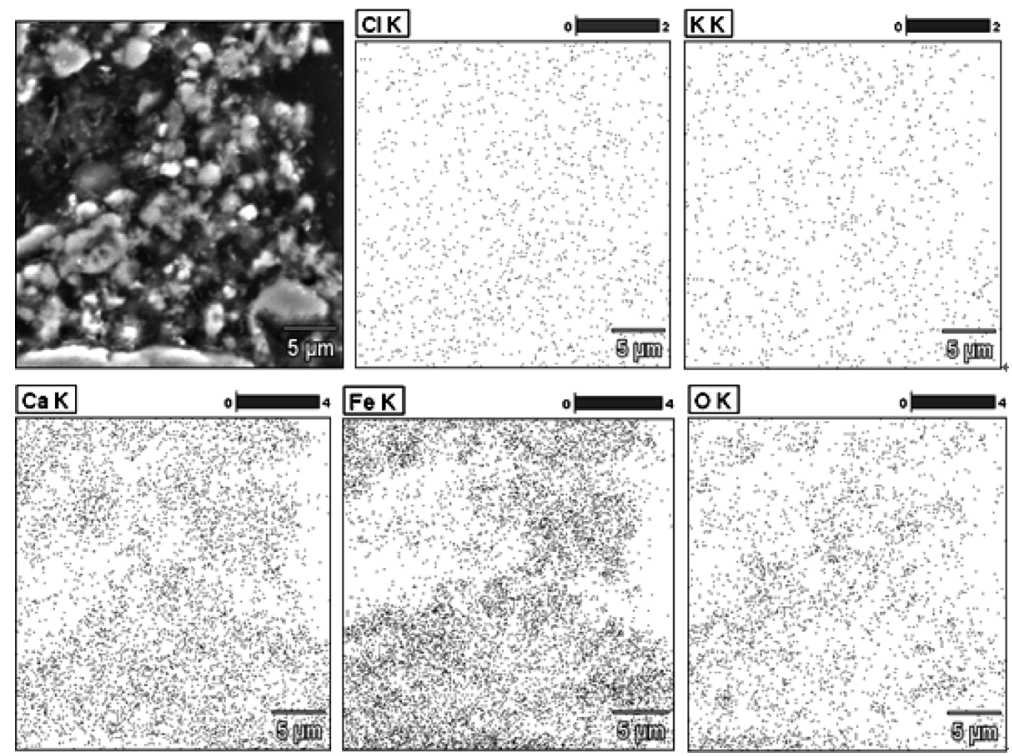

Fig. 4. SEM X-ray mapping of the water washed dust.

Table 3. Selected characteristics of as-received ESP dust.

\begin{tabular}{|c|c|c|c|c|c|c|c|}
\hline Parameter & $\begin{array}{c}\text { Multiple } \\
\text { point BET } \\
\text { surface area }\end{array}$ & $\begin{array}{l}\text { Single } \\
\text { point } \\
\text { BET } \\
\text { surface } \\
\text { area }\end{array}$ & $\begin{array}{c}\text { Pore } \\
\text { volume }\end{array}$ & $\begin{array}{l}\text { Apparent } \\
\text { skeletal } \\
\text { density }\end{array}$ & $\begin{array}{c}\text { P90 } \\
\text { value }\end{array}$ & $\begin{array}{c}\text { Largest } \\
\text { particle } \\
\text { size }\end{array}$ & $\begin{array}{c}\text { Smallest } \\
\text { particle } \\
\text { size }\end{array}$ \\
\hline $\begin{array}{c}\text { Value } \\
\text { obtained }\end{array}$ & $4.58 \mathrm{~m}^{2} / \mathrm{g}$ & $3.88 \mathrm{~m}^{2} / \mathrm{g}$ & $0.016 \mathrm{~cm}^{2} / \mathrm{g}$ & $2.52 \mathrm{~g} / \mathrm{cm}^{3}$ & $26.4 \mu \mathrm{m}$ & $46.1 \mu \mathrm{m}$ & $1.29 \mu \mathrm{m}$ \\
\hline
\end{tabular}

high pore volume, the result of which is low bulk density and high porosity, whereas the skeletal density is over $2.52 \mathrm{~g} / \mathrm{cm}^{3}$. These parameters have various implications for water leaching.

\subsection{Water Leaching}

Water leaching experiments were done to the ESP dust at different temperatures, various initial particle size, various stirring speed and different leaching solid liquid ratios, and the leaching kinetics was investigated by monitoring the electrical conductivity variation with leaching time at different leaching conditions (the results not shown). The results show that this leaching process is just dissolution of the water soluble constituents including $\mathrm{KCl}, \mathrm{NaCl}$ and so on. The mechanism of the leaching process was presumed as illustrated in Fig. 5.

In the initial stage of the leaching process, loosely agglomerated structure was formed consisting of the primary particles weakly attached with each other by van der Waals and capillary adhesive forces. Then the aggregates gradu- 


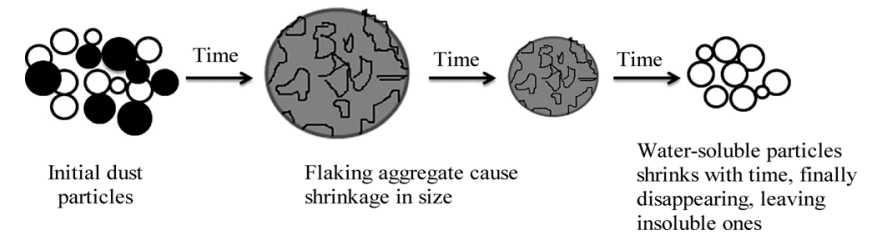

Fig. 5. Dissolution mechanism of ESP dust particles during water leaching process.

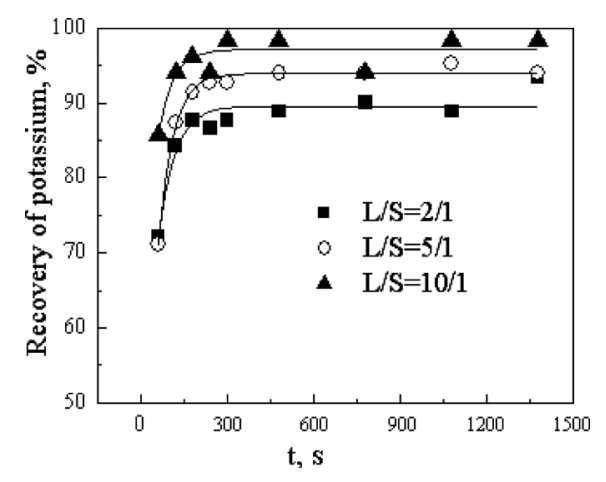

Fig. 6. Effect of $\mathrm{L} / \mathrm{S}$ ratio on leaching rate of $\mathrm{K}$ element at $303 \mathrm{~K}$ with stirring speed of $550 \mathrm{rad} / \mathrm{min}$.

ally shrink because of dissolution of some water-soluble particles with diffusion of water from the particle pore space into the bulk solution. Under powerful stirring, watersoluble particles disappear at last, and the insoluble residues were left.

Effect of the L/S ratio on potassium recovery percentage was shown in Fig. 6. As expected, almost all the potassium in the dust can be recovered by water leaching when the L/S ratio is big enough, which again confirms that the potassium in the dust exists in the form of $\mathrm{KCl}$. In addition, leaching recovery of potassium decreases to $89 \%$ when the $\mathrm{L} / \mathrm{S}$ ratio decreases to $2 / 1$. So it is important to wash the filter cake adequately in order to assure the recovery of $\mathrm{KCl}$ in the dust as high as possible.

However, it was found that in total $40 \%$ (weight percent) of the dust was dissolved into the water. That is to say, except $\mathrm{KCl}$, there are some other constituents dissolved. Similar results were in fact obtained in SEM X-ray mapping analysis section, chloride distribution wider than potassium distribution, which means chloride contribution is not only due to formation of $\mathrm{KCl}$, and there are other chlorides existed in the dust. It was confirmed by sampling and analyzing composition of the leaching liquor during the leaching process, the results are shown in Fig. 7.

It is clear to see that leaching equilibrium of potassium, calcium and sodium can all be achieved in five minutes, and the amount of potassium leached is higher than that of calcium and sodium. Bruckard et al. reported that most of the potassium is present as $\mathrm{KCl}$, only half of the sodium is present as $\mathrm{NaCl}^{3}{ }^{3)}$ In this work, both potassium and sodium are present in chlorides, because their leaching amount is close to the total amount analysis results in Table 2. And the great contribution disparity between potassium and sodium is good for purification of $\mathrm{KCl}$ by fractional crystallization.

In order to make sure potassium chloride dissolved completely and concentrate the leachate at the same time, coun-

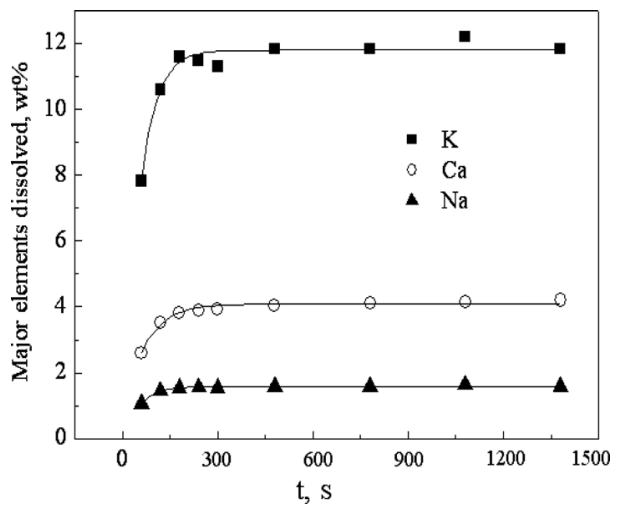

Fig. 7. Comparison of available leaching content of potassium, calcium and sodium as a function of leaching time.

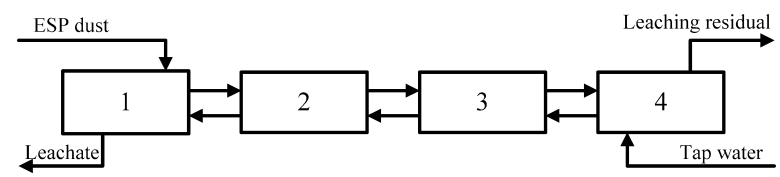

Fig. 8. Countercurrent leaching diagram.

tercurrent leaching using stages is taken, which is one of the most leaching methods. Actually the solid is not moved physically from stage to stage, the charge in any one cell is treated by a succession of liquids of constantly decreasing concentrations as if it were being moved from stage to stage in a countercurrent system. ${ }^{20)}$ Figure 8 shows the materialbalance diagram for the four stages countercurrent cascade in this leaching. The stages are numbered in the direction of flow of the dust. The water phase overflows in a direction counter to that of the dust, dissolving the water-soluble ones, such as $\mathrm{KCl}$, as it moves from stage four to stage one. It was obtained that leaching equilibrium can be obtained in five minutes if proper stirring speed and liquid solid ratio is selected. So for ESP dust leaching, it is not difficult to understand that $\mathrm{KCl}$ in the dust can be completely transferred into the leaching solution and the leaching residual can be washed thoroughly by countercurrent leaching.

\subsection{Separation of $\mathrm{KCl}$ from the Impurities}

As mentioned in Sec. 3.6, water washing of ESP dust not only removes almost all the potassium chloride, but sodium chloride, part of calcium chloride, and slight amount of zinc, copper, lead, manganese and cadmium were leached. The presence of these heavy metals in the liquor undoubtedly raises environmental concerns regarding their disposal and affect purity of $\mathrm{KCl}$ product if the leach liquor was directly evaporated for $\mathrm{KCl}$ crystallization. Here sodium sulfide was used to precipitate the heavy metals, which is a traditional way to remove heavy metals from waste water. It was found that most of the heavy metals were removed by this method, and the precipitation equilibrium was achieved in only several minutes. The comparison of ion concentration in the leach liquor and that after sulfide precipitation was made and listed in Table 4.

As can be seen from Table 4, compared with the initial concentration of these ions in the leach liquor, concentration of $\mathrm{KCl}$ and $\mathrm{CaCl}_{2}$ nearly keeps constant, $\mathrm{NaCl}$ concentration increases a little due to addition of the slight amount of sodium sulfide, and concentration of $\mathrm{Pb}, \mathrm{Zn}, \mathrm{Cu}$ and $\mathrm{Cd}$ 
ISIJ International, Vol. 49 (2009), No. 5

Table 4. Comparison of ion concentration in the leach liquor (with L/S ratio of 1/1) before and after sulfide precipitation.

\begin{tabular}{cccccccc}
\hline Constituents & $\begin{array}{c}\mathrm{KCl}, \\
\mathrm{g} / \mathrm{L}\end{array}$ & $\begin{array}{c}\mathrm{NaCl}, \\
\mathrm{g} / \mathrm{L}\end{array}$ & $\begin{array}{c}\mathrm{CaCl}_{2}, \\
\mathrm{~g} / \mathrm{L}\end{array}$ & $\begin{array}{c}\mathrm{Pb}, \\
\mathrm{mg} / \mathrm{L}\end{array}$ & $\begin{array}{c}\mathrm{Zn}, \\
\mathrm{mg} / \mathrm{L}\end{array}$ & $\begin{array}{c}\mathrm{Cu}, \\
\mathrm{mg} / \mathrm{L}\end{array}$ & $\begin{array}{c}\mathrm{Cd}, \\
\mathrm{mg} / \mathrm{L}\end{array}$ \\
\hline $\begin{array}{c}\text { Concentration } \\
\text { in the leach } \\
\text { liquor }\end{array}$ & 206 & 46 & 24.7 & 504.9 & 176.6 & 215.1 & 16.8 \\
\hline $\begin{array}{c}\text { Concentration } \\
\text { after sulfide } \\
\text { precipitation }\end{array}$ & 205 & 51 & 24.5 & 2.9 & 0.9 & 0.3 & 0.2 \\
\hline
\end{tabular}

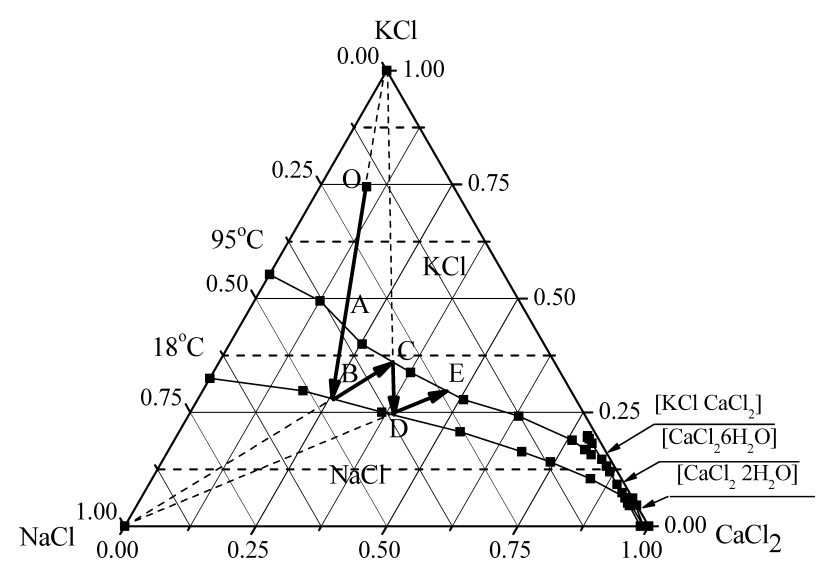

Fig. 9. Phase diagram of system $\mathrm{KCl}-\mathrm{NaCl}-\mathrm{CaCl}_{2}-\mathrm{H}_{2} \mathrm{O}$ at $18^{\circ} \mathrm{C}$ and $95^{\circ} \mathrm{C}$.

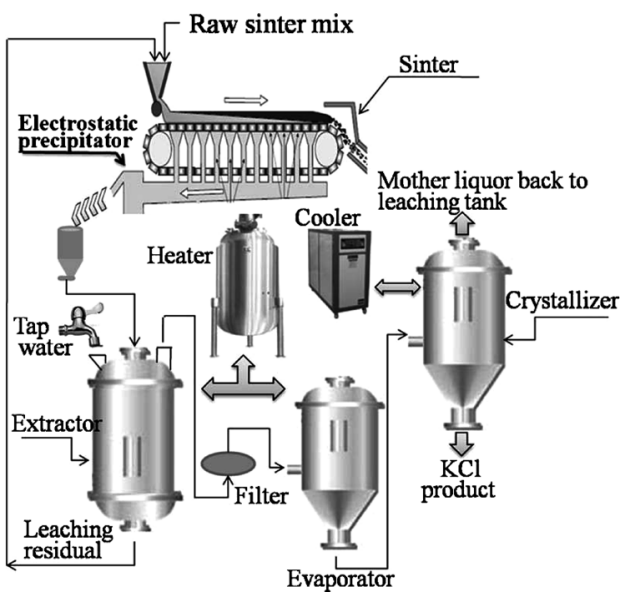

Fig. 10. Schematic diagram of the demonstration unit for the EPS dust treatment.

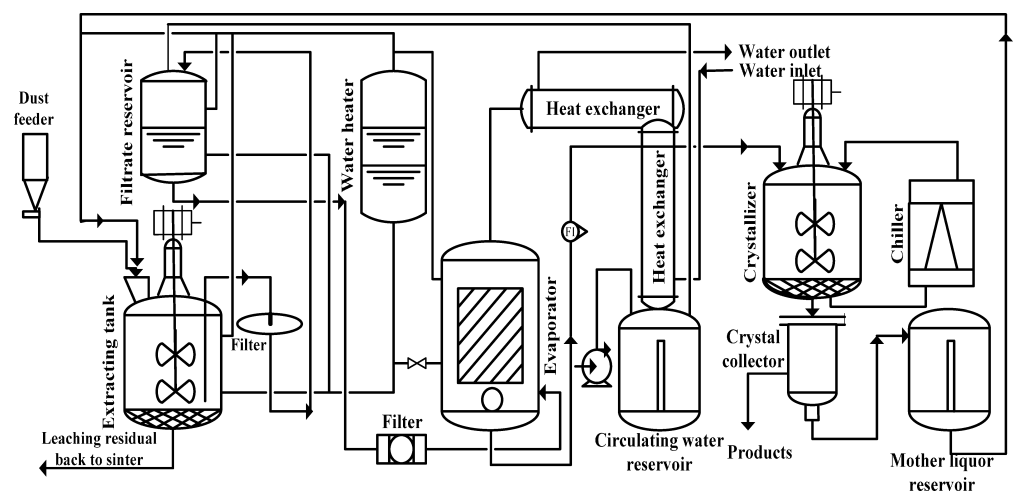

Fig. 11. Process flow diagram of the demonstration unit for the EPS dust treatment.

was decreased from $504.9,176.6,215.1$ and $16.8 \mathrm{mg} / \mathrm{L}$ to $2.9,0.9,0.3$ and $0.2 \mathrm{mg} / \mathrm{L}$ respectively.

After removing most of the heavy metals, the leach solution can be perceived as mixture of $\mathrm{KCl}, \mathrm{NaCl}$ and $\mathrm{CaCl}_{2}$. According to dry basis phase diagram of system $\mathrm{KCl}-$ $\mathrm{NaCl}-\mathrm{CaCl}_{2}-\mathrm{H}_{2} \mathrm{O}$, as shown in Fig. 9, it is found that the initial composition of the leaching solution (Point $\mathrm{O}$ in Fig. $\left.9, \mathrm{CaCl}_{2} / \mathrm{NaCl} / \mathrm{KCl}=0.089 / 0.166 / 0.744\right)$ is located in the $\mathrm{KCl}$ crystalline region both at 18 and $95^{\circ} \mathrm{C}$. Firstly the leaching solution was evaporated at $95^{\circ} \mathrm{C}$, and in this process only $\mathrm{KCl}$ was seeded out until to point $\mathrm{A}$, which is on the two phase equilibrium line of $\mathrm{KCl}$ and $\mathrm{NaCl}$. So the final point of the evaporation process should be controlled before point $\mathrm{A}$, and still $\mathrm{KCl}$ was seeded out when it began to crystalline by cooling at $18^{\circ} \mathrm{C}$ or even at lower temperature with the help of a chiller-crystallizer. Similarly, the final point of the cooling crystallization should be ended before point $\mathrm{B}$. Then $\mathrm{NaCl}$ can be obtained by evaporating the mother liquor at $95^{\circ} \mathrm{C}$, thus $\mathrm{KCl}$ and $\mathrm{NaCl}$ were separated. In the same way, further separation of $\mathrm{KCl}$ and $\mathrm{NaCl}$ can be obtained along with operation line $\mathrm{CD}$ and $\mathrm{DE}$, and so forth. In this separation process, concentration of $\mathrm{CaCl}_{2}$ was inevitably increased, and it was accumulated when the mother liquor was returned to the extraction process as leaching reagent. Therefore, it is necessary to find an outlet for $\mathrm{Ca}^{2+}$. Here $\mathrm{K}_{2} \mathrm{SO}_{4}$ was selected as the precipitating agent, and it was proved practicable to remove part of $\mathrm{Ca}^{2+}$ from the system by produce of $\mathrm{CaSO}_{4} \cdot 2 \mathrm{H}_{2} \mathrm{O}$. However, it is found necessary to control mole ratio of $\mathrm{SO}_{4} / \mathrm{Ca}$ at $0.9-1$. Excessive $\mathrm{K}_{2} \mathrm{SO}_{4}$ addition resulted in potassium loss by producing a new phase called syngenite $\left(\mathrm{K}_{2} \mathrm{SO}_{4} \cdot \mathrm{CaSO}_{4}\right.$. $\left.\mathrm{H}_{2} \mathrm{O}\right)$ rather than gypsum $\left(\mathrm{CaSO}_{4} \cdot 2 \mathrm{H}_{2} \mathrm{O}\right)$.

\subsection{Description of Demonstration Unit}

On the basis of the present data, a demonstration unit with a handling capacity of $10 \mathrm{~kg} / \mathrm{h}$ for extracting, separating and recovering $\mathrm{KCl}$ from the ESP dust was designed and made in the lab. The schematic diagram and process flow sheet of this technology are shown respectively in Figs. 10 and 11. This technology can be divided into three 
Table 5. Elemental concentrations in the leaching residual of ESP dust.

\begin{tabular}{ccccccccc}
\hline Elements & $\mathrm{K}$ & $\mathrm{Na}$ & $\mathrm{Ca}$ & $\mathrm{Mg}$ & $\mathrm{Zn}$ & $\mathrm{Pb}$ & $\mathrm{Fe}$ & $\mathrm{C}$ \\
\hline Composition,wt\% & 0.20 & 0.16 & 9.38 & 1.50 & 0.33 & 1.47 & 36.2 & 4.5 \\
\hline Elements & $\mathrm{Si}$ & $\mathrm{S}$ & $\mathrm{Al}$ & $\mathrm{Cu}$ & $\mathrm{Mn}$ & $\mathrm{Ti}$ & $\mathrm{P}$ & $\mathrm{Ni}$ \\
\hline Composition,wt\% & 2.93 & 1.98 & 7.60 & 0.065 & 0.22 & 0.10 & 0.108 & $/$ \\
\hline
\end{tabular}

parts, extracting, evaporating and crystallization.

For the first part, the ESP dust was fed to the extracting tank followed by a proper amount of tap water, under a given stirring speed, the leaching process lasted for about half an hour. Then the leaching liquor was separated from the residual with a filter after settling for another half an hour. The leaching process is to be accomplished by countercurrent leaching using stages, as discussed in Sec. 3.6. Here in the diagram of Fig. 10, this process is not shown in detail. After the liquid solid separation, the leaching residual released from the bottom of the tank, with enriched $\mathrm{Fe}$ and $\mathrm{C}$, was returned to the sinter plant for reuse. Composition analysis results of the leaching residual are shown in Table 5. In contrast with the results given in Table 2, it can be clearly seen that Fe concentration has been increased from $21.7 \%$ in the as-received dust to $36.2 \%$ in the leaching residual of the dust.

The leachate obtained through the four-stage countercurrent leaching was prepared for heavy metals removal, which was also processed in the leaching tank. And the liquid solid separation in this step is finished in the same way as that in the leaching step. The separated liquor was directly sent into the evaporator with the help of a vacuum air pump. In the evaporating process, the extracted and purified $\mathrm{KCl}$ solution with small amount of impurities was further concentrated under a pre-set vacuum degree. Then the concentrated solution was sent to the crystallizer. A chiller provided the cooled water or solution for the crystallizer of which the lowest temperature can get to ten below zero. At last, the crystallized product was arrested at a small tank with a filter under the crystallizer, and the mother liquor was collected in a special reservoir before returning it to the extracting tank.

As a side note, in the demonstration unit, the water heater tank was used for keeping the temperature of the leaching liquor at the requested value, usually $90^{\circ} \mathrm{C}$. However, when the demonstration plant was constructed in iron and steel making works, the water heater can be set aside, since the required heat can be provided by the waste heat come from various high-temperature operation plants in the iron and steel making works.

$\mathrm{KCl}$ product with a purity of $96.5 \%$ was thus produced. Figure 12 gives the photos of both the $\mathrm{KCl}$ product recovered from the sintering dust and an analytically pure $\mathrm{KCl}$ purchased from the market. And the photos were made by using a microscope of ZEISS 232. Although due to difference in purity, distribution of the $\mathrm{KCl}$ particles recovered from the sintering dust is not so even as that of the analytically ones, particle size and color of them are much the same.

However, there is still a lot of work to do, such as to ascertain the treatment way of the sulfides obtained by sodium sulfide precipitation, water balance for continuous

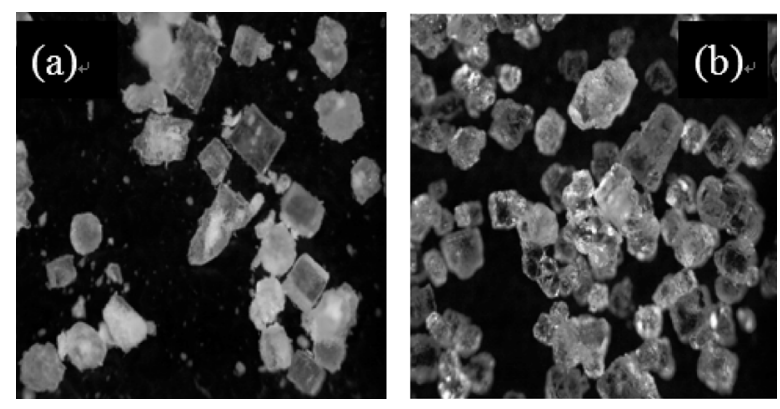

Fig. 12. (a) Photo of $\mathrm{KCl}$ product recovered from the sintering dust; (b) photo of analytically pure $\mathrm{KCl}$.

operation and the optimized condition for complete separation of $\mathrm{KCl}$ and $\mathrm{NaCl}$.

\section{Conclusions}

Test-work was conducted on a sample of ESP dust, which contained $22 \%$ potassium chloride, in a bid to devise a simple and robust process to recover potassium from the dust and upgrade the iron content of the dust so that it would be more acceptable to the sinter. Results indicate that a relatively simple flow sheet could achieve these aims.

It was found that water leaching of the dust with a liquid solid ratio of $2 / 1$ for only $5 \mathrm{~min}$ removed approximately $90 \%$ of the potassium chloride in the dust. With resort to a counterpart extraction method, nearly all the potassium chloride can be leached out. However, it was obtained that about $40 \%$ of the feed weight was in the leach solution. This apparently gave upgrading of the iron level in the leach residual, but at the same time suggesting that other water-soluble salts were also removed from the dust. The washed solids could be returned to the sinter for reuse. And the leaching solutions were subjected to a simple treatment by sodium sulfide to remove heavy metals before evaporation. After removing the heavy metals, the solution can be perceived as system $\mathrm{KCl}-\mathrm{NaCl}-\mathrm{CaCl}_{2}-\mathrm{H}_{2} \mathrm{O}$. $\mathrm{KCl}$ was obtained by firstly evaporation and then fractional cooling crystallization. In view of concentration of calcium in the mother liquor with seeding out of $\mathrm{KCl}$, potassium sulfate was selected as precipitating agent of calcium ions. This proposed flow sheet is proved feasible by the demonstrated unit studies, and $\mathrm{KCl}$ product with a purity of $96.5 \%$ is obtained.

\section{Acknowledgements}

The authors would like to thank Ministry of Education for the financial support and Laiwu steel, Ji'nan steel and Bao steel by handing ESPD sample for the study. 


\section{REFERENCES}

1) C. Peng, Z. C. Guo and F. L. Zhang: ISIJ Int., 48 (2008), 1398.

2) T. Havlík, B. V. Souza, A. M. Bernardes, I. A. H. Schneider and A. Miškufová: J. Hazard. Mater, B135 (2006), 311.

3) W. J. Bruckard, K. J. Davy, T. Rodopoulos, J. T. Woodcock and J. Italiano: Int. J. Miner. Process, 75 (2005), 1.

4) G. Laforest and J. Duchesne: J. Hazard. Mater, B135 (2006), 156.

5) N. Leclerc, E. Meux and J. M. Lecuire: J. Hazard. Mater, B91 (2002), 257.

6) Y. C. Zhao and R. Stanforth: J. Hazard. Mater, B80 (2000), 223.

7) C. Jarupisitthorn, T. Pimtong and G. Lothongkum: Mater. Chem. Phys., 77 (2002), 531.

8) O. Gokhan: Hydrometallurgy, 78 (2005), 236.

9) J. R. Cui and L. F. Zhang: J. Hazard. Mater., 158 (2008), 228.

10) C. S. Kirby and J. D. Rlmstidt: Environ. Sci. Technol., 28 (1994), 443.

11) J. M. Kim and H. S. Kim: J. Eur. Ceram. Soc., 24 (2004), 2373.
12) J. J. Dijkstra, H. A. V. Sloot and R. N. J. Comans: Appl. Geochem., 21 (2006), 335.

13) D. Bendz, P. L. Tüchsen and T. H. Christensen: J. Contam. Hydrol., 94 (2007), 178.

14) N. Menad, H. Tayibi, F. G. Carcedo and A. Hernandez: J. Cleaner Prod., 14 (2006), 740.

15) B. A. Zeydabadi, D. Mowla, M. H. Shariat and J. F. Kalajahi: $H y-$ drometallurgy, 47 (1997), 113.

16) A. J. B. Dutra, P. R. P. Paiva and L. M. Tavares: Miner. Eng., 19 (2006), 478.

17) A. A. Masud: Miner. Eng., 15 (2002), 945.

18) N. Leclerc, E. Meux and J. M. Lecuire: Hydrometallurgy, 70 (2003), 175.

19) O. Ruiz, C. Clemente, M. Alonso and F. J. Alguacil: J. Hazard. Mater, 141 (2007), 33.

20) W. L. McCabe, J. C. Smith and P. Harriott: Unit Operations of Chemical Engineering. McGraw-Hill, New York, (2001), 742. 